\title{
(x)
}

Qualitative Sociology Review

Volume III, Issue 3 - December 2007

DOI: https://doi.org/10.18778/1733-8077.3.3.05

Emmanuel Grimaud

Centre National de la Recherche Scientifique, Paris

\section{The Film in Hand Modes of Coordination and Assisted Virtuosity in the Bombay Film Studios}

\begin{abstract}
Less has been said about the hand movements of the film makers, their cultural dimension and the place of this "corporate language" in the film making process, probably because this object is difficult to capture even with a diary. Gestures go too fast to be sketched on the spot and often faster than the perception of the ethnographer. Some of these gestures are made to stabilize the frame or simulate the camera movement but lots of them are difficult to classify and don't fall into this category, like the ones which are produced to accompany the actors' action or to invite him to perform a certain action and which have more to do with a mode of demonstration involving the entire body. This article, mostly based on videos of Bombay film makers at work, tries to identify the specificity of these gestures in terms of communication or interaction and their potential of coordination in the film set dynamics.
\end{abstract}

\section{Keywords}

Gesture; Demonstration; Film set; Shooting; Bombay; Ethno(video)graphy

As for the fact that I work on the scenario with my collaborators and avoid letting the actors read it, that's the result of experience. l've noticed that when actors can read the scenario at home in the evening, in front of a mirror, helped by family members, they adopt certain facial expressions that are absolutely not right. So, if possible, I prefer for the actors to arrive completely blank, without their own fixed idea of the character, which absolutely could not be the same as mine, or at the best of times quite different.

Federico Fellini 
On a film set, every one must know his job, but doesn't need to know what the film is about. Professionals working on a film set have very unequal knowledge of the images the director has in mind, and a large part of the production team's work consists in mutually persuading each other and then persuading the other professionals of the feasibility of the image to be realised. It would certainly be difficult if the director had to explain his script to each and every lighting attendant. When a shot is decided, the information is distributed to the technicians through an army of assistants. This challenge is tackled in different ways according to the teams involved. Some teams hold countless sessions of brainstorming and collective narration before and between shoots, but it is also common for production assistants to blame their director for a lack of clarity, for continually changing his mind or for being confused, or for actors making several films a day to learn about the scene they are going to shoot just a few minutes before facing the camera. The invention of the screenplay and its celebration as the instrument of reason, capable of taming the cinematographic imagination, has changed this uncertainty but not removed it, for even when the work of writing is carried out in the rules of the art and the screenplay is transformed into a scenario and then into shot lists, the same operation of shared visualisation on the film set still has to take place, and the concrete gestures of the actor must still be decided. Added to which, the factors hindering the successful realisation of the script inevitably multiply during shooting, and it is very rare for a film to be the smooth execution of a preconceived plan. At best it comes close, but it is never equivalent. The film set therefore produces alternative methods for providing those who need it with the most up-to-date information about the schedule to be followed.

The Bombay film studios have sometimes gone quite far in experimenting the possibility for the actors to arrive "completely blank" on the set, for reasons that we shall explain more clearly later. And the film directors have come to use interesting ways of demonstrating to the actors what they have to do, especially in the field of choreography and stunt direction. The purpose of this article is to analyse the place of these intermediary settings and modes of demonstration in the film-making process. My material consists in video footage of filming in which we can see actors, directors and assistants interacting to convince each other what should be done at different moments of the take. Most of them were filmed during my research study in the studios of Bombay where I worked as an assistant director (Grimaud 2004). The reader might find in the following pages an answer to this enigmatic question: - how have the Bombay film studios become one of the most prolific industries in the world? This question has prompted many Hollywood production houses to send industrial spies to Bombay to discover their "secrets of production". Part of the answer could lie in the solid learning devices that spontaneously take place on the film set to find out what the shot is about, involving not only the director and the actors but also those who surround them (assistants, doubles, supporting men), who play an important role in ensuring that the actors acquire the right skills, the action or gesture that makes the difference. 


\section{The making of: an Authorised Disclosure Zone (ADZ)?}

Before analysing the videos that I have shot to capture the demonstrative universe of the film set at different moments, I would like to make a few remarks regarding the possibility (or impossibility) of using the making-ofs available in the market as ethnographic material. Although I spent several years working as a production assistant, I had great difficulty in filming the interactions that take place on the set in Bombay. Strangely, it is easier to learn how films are financed (an open secret in Bombay), and to make a film on this subject by interviewing important personalities, to understand the pressure exerted by gangs (who go as far as telling the actors or producers what scenes to do over the telephone), to see a producer persuade an actor to take part in a film with the help of a princely sum of money or to see the latter accept for sometimes rather disreputable reasons, than it is to focus one's attention on the other side of the camera. This paradox is easy to explain. Today, the "making-of" has become an obligatory exercise for the big production companies, which add a few excerpts of the filming process to the films they distribute. And if everyone knows that crime syndicates have long been financing the production of films, then revealing the fact, even on film, amounts to beating a dead horse. In filming a shoot, on the other hand, there are commercial interests at stake, and the director is loath to allow pictures of his film sets to leave the production company before the film's release, because the scenario or the set could be plagiarised by someone else.

The stakes of the disclosure are not the same. Ironically, the zone that must be protected from the over-curious gaze is not situated where one would expect it to be, at the level of the procedures of financing, the workings of crime syndicates and the mechanisms of intimidation weighing on the production. The secret lies in that vulnerable interstice between the camera and what lies behind it, where one can capture, steal and misuse images of the actors at work and grasp the artistic turmoil in which the director tries to transform a screenplay into pictures.

Most of the making-ofs released by production companies are intended to show the actors in a more natural setting, to humanise them away from the spotlights or to emphasise the pleasure they have in working with one director or another. They rarely bring to the surface the hesitant work of conceiving and orientating the gestures of the actors in their interaction with the production team or the conflict and uncertainty that any production is bound to experience at one time or another. Cleverly orchestrated, the making-of, in its current form, remains on the surface, within an authorised disclosure zone, generating its own secrets by never showing everything, not even the dynamic through which the images observable in situ, on the set, are formed.

It is always interesting to follow a team making a making-of, if only to realise that a film set differs from a theatre stage in the mass of technical equipment that weighs on the performance and in the fragmentation of the acting, subjected to the harsh law of the cut. The cut is a powerful tool in the constitution of the world of the film set, imposing a special rhythm and providing the making-of with its raison d'etre and its effectiveness. And because the camera captures the actor at a certain, necessary distance, the actor thus "objectified" is deprived of the key to judging his own performance, so that he must abandon himself to the judgement of those who magnify him through the camera. And this is why the other side of the camera is not only the locus of capture of a well-defined interaction, but also a place of control and persuasion. Intense interactions between the cameraman, the director and the actors can thus take place between takes, to orientate the performance of the actors. In the 
theatre, the director can rarely intervene in this manner, once the play has got under way. The back of the camera and the back of the theatre do not share the same status. Theatre rehearsals do have an equivalent in the movies, in a multiplied, chopped-up and accelerated form, between takes, but the back of the stage is there to accompany a performance, whereas the back of the camera provokes the performance and puts it "in the can", to be rearranged again later, in the editing studio.

Different from the making-of, the continuity video throws an interesting light on the way that filming "censors" its own process while it is taking place. It is often used by the director's assistants to check the continuity between shots and to enable all the elements in a scene to be verified. A support used in all modern filming, destined for internal use by the production team, the continuity video records the shots from the camera's point of view, to constitute a baseline that can be consulted at any time. Continuity assistants who amuse themselves by filming what happens in between takes may be accused of overstepping their functions and wasting film. Continuity videos show the repetitive dimension of the takes and the way that gestures become consolidated through repetition. Actors have to perform the same gestures several times before a good take is filmed. Most continuity videos are slightly out of kilter and clumsy, because they are filmed under rushed conditions and because it is difficult for the continuity assistant to reproduce the camera viewpoint exactly.

\section{See ${ }^{[1]}$ video clip 1 http://www.qualitativesociologyreview.org/ENG/Volume8/videos/video1.php}

But the continuity video does not give us access to the motives which lead directors to repeat a given take or, for that matter, to their underlying mechanisms of demonstration, even if we do catch glimpses, in the previous clip, of a choreographer and his assistant accidentally filmed while demonstrating the right gestures to the actors before the latter take their places in front of the camera. This work of incorporation is supposed to make sense in the final image, which effaces it, or pushes it out of the frame by its very arrival, and producers rarely see fit to include more than snippets of it in the ADZ.

All pictures obliterate their reverse side, at the very same time as they take form. The more progress the film makes, the more the history of the filming becomes complicated and the work of demonstration and persuasion required takes on the aspect of a trade secret.

\section{Opening the black box of the film shot}

One way to open the black box of the film shooting process is to focus on the film makers' working gestures while they are devising a shot. Filmmakers move beyond speech, communicating by means of a sort of sign language when they want to visualise their images or explain them to others. When the time comes to shoot the film, the screenplay is an old memory. Largely internalised and assimilated, it must now be expressed in concrete images. To realise the shots they have in mind and ensure that their instructions are understood by the cast and crew, filmmakers have a singular way of taking the set in hand, using gesticulations or manual demonstrations

\footnotetext{
${ }^{1}$ Technical note: all video clips presented in this article are available at the journal's website. Internet access and windows media player (.wmv) compatible plug-in are required. To watch the videos just click on the link. It typically takes one or two minutes to download. If you are not able to watch the videos online, download them using a proper URL from the appendix.
} 
(Mac Neill 1992; Rosental 2005). The action to be performed must be made visible to the actor, explained several times, corrected and modified so that it becomes definitively fit to be shown. And this is achieved by means of relays (assistants, stand-ins) who rarely appear in the finished film, unless they are given minor parts to play (one of the hoodlums who gets beaten up, one among several dancers in a ballet). The most complex systems of demonstration are those of the choreographers and stunt directors, of which we shall see a few examples later.

The moments of demonstration on a film set are always very intense, but relatively difficult to describe in a simple notebook. Video seems particularly appropriate, because we can replay movements in slow motion, describe the gestures more precisely and grasp their "interstitial" quality (Piette 1996; Goodwin 2003). In slow motion, the coordinating aspect of these gestures can be seen more clearly. Without the hands and their clarification of the way the camera field should be organised and its different elements positioned, no take would be possible. Rather than a language, this set of gestures that directors use to communicate the actions they visualise more clearly would be better described as a singular kind of "demonstration scaffolding", for although it does use signs reminiscent of deaf and dumb language (Delaporte 2002), which are immediately understood by people in the profession, it also uses a large amount of trial and error, gestures of exhortation and body stances with the aim of persuading the actor to do what the director wants, and these cannot be reduced to the automaticity of a sign language (Hutchins and Palen 1997; Haviland 1993). Working gestures and intermediary devices that are erected around the actors to enable them to make the right gesture or expression at the right time can be considered as temporary constructs that are made for the realisation of the shot, but in certain cases, we shall see that the link between these scaffolds and the final result is not only one of transformation. By looking closely at that which is explained or expressed through the setting up of "demonstration scaffoldings" (Vigotsky 1934) and which could not be communicated otherwise, we shall see how the film set stands out as an original medium of human manipulation, where director and actors try out singular methods of influence. When directors start using their hands (and their feet, shoulders, hips, etc. - because when it comes to demonstration, there are no holds barred), something happens which sociology and film theory have curiously neglected and which concerns, more generally, all the procedures used in situ for the purposes of persuasion.

\section{Take a scenario in hand}

\section{See video clip 2 http://www.qualitativesociologyreview.org/ENG/Volume8/videos/video2.php}

Now let us take the shot designing process at different stages and start with a first video clip. In this first clip, a screenwriter is explaining the scenario to a replacement cameraman who has just arrived on the shoot. Here, the replacement cameraman knows absolutely nothing about the film he is to work on, and he is being briefed. He has been told that he will be filming an action scene, but that is all he knows. The time between takes is quite long enough for this catching-up, and if the newly-arrived cameraman contents himself with doing what he is asked during the first takes, it only takes a brief time, and a "session" with the screenwriter, for him to become a creative partner for the director, making his own suggestions of camera angles. They are on the site of filming, and the account the screenwriter gives to the cameraman refers to positions that can be immediately visualised and makes use of gestures that are commonly used by other screenwriters when they have to relate an 
episode or story vocally. Here, the word and the gesture take over from the screenplay and writing operations. The hand accompanies, designates and moves the camera and the actors, but at the same time it does more, for it can express the energy of a story, the rhythmicity of the action and the effect the action has on the spectator. The scene thus gesticulated becomes more than a proposal, it becomes a veritable incitement to action, and having just arrived, the cameraman finds himself immediately faced with a gestural world and the constraint of choosing camera angles in a real space, whereas if he had read the screenplay that he had, perhaps, received beforehand, he would probably not have been so quick to start thinking about its execution. "We follow the hero Ajay, he grabs a guard standing there from behind, hits him, throws him over there and runs off with the child", narrates the screenwriter. The scene has been pre-digested, ready to be executed. The cameraman does not need to be told much to grasp the film in progress and propose new options. Many sequences are confirmed and reworked in this way during the "dead time" provided by the material organisation of the take and its appropriation by the actors, as the following clip shows. Here, the action coordinator is explaining the take to an assistant.

See video clip 3 http://www.qualitativesociologyreview.org/ENG/Volume8/videos/video3.php

The following paragraphs will show that it is not always necessary to know the screenplay of a film in order to work on the shoot as a technician or even, to a certain extent, as an actor. In Bombay, where actors often work on several different films in one day, their knowledge of the screenplay may be quite vague, although they would never admit this. But on the set, there are several safeguards that allow the actors to remedy this ignorance and to learn enough on the set to shoot the day's schedule.

\section{Making a frame out of one's fingers}

Let us now move forwards in the process of realising the take. Here, the procedure differs little from one shoot to another. The take is proposed and conceived by the director (and his assistants and, if need be, the choreographer or action coordinator) and then translated into directions to the different departments (lightmen, set assistants).

See video clip 4 http://www.qualitativesociologyreview.org/ENG/Volume8/videos/video4.php

The director, preoccupied by the conception of the shot, rarely troubles himself with communicating it to the different professionals involved; he delegates this tedious work to someone else. It is up to his first assistant to issue the orders, as soon as he thinks the shot has been more or less defined. Usually, the director decides the shot in company with the cameraman, moving the frame around virtually with his fingers.

This gesture by which the screen is materialised may occur during the "creative wandering", when the director paces up and down the set looking for new ideas and better camera angles, or once he has conceived the action. It then helps to test or to project what he has in mind and to convince the others that they are seeing the same thing. The difficulties of shared visualisation on the set are thus resolved by operations that vary little from one shoot to another: tracing the picture in the air, framing space, delimiting the contours of the image and the movements (tracking, 
high-angle, low-angle, tilt shots, etc.). We can find the same operations among so many filmmakers that we can consider it a routine mode of expression.

See video clip 5 http://www.qualitativesociologyreview.org/ENG/Volume8/videos/video5.php

The hand is the essential tool of simulation. It can be used to experiment a movement in space or to shift the camera position virtually, without really having to move it, and so to make the camera movements present to the technicians involved. At the same time, it helps everyone to reach agreement about speeds, tracking in or out, changes in focus, etc. At this stage, the director and cameraman usually simulate the scene to be filmed with their assistants, giving an extra degree of physicality to the planned take. However, the frame thus materialised, which has been enough to convince the director's collaborators, may be no more than an illusion of the final take. The director may subsequently realise that there are better camera angles than the one chosen, especially if the actor is not on the set and this preliminary work of positioning is done without him. The hand, held up to the eye like a frame, a sign that the image is about to emerge, is the ultimate reference for convincing the others and it accompanies filmmakers in their many decisions.

\section{Moving the set by gestures}

Now let us watch a fifth clip, filmed when the take really has been decided, the position of the camera has been fixed and all that now remains to do, for the shooting area to materialise definitively, is to adjust the parameters of the take in relation to each other.

See video clip 6 http://www.qualitativesociologyreview.org/ENG/Volume8/videos/video6.php

The assistant director's gestures for placing the lights have to be repeated several times, until the right positions are found: "forward", "more to the left"... These pointing operations and gestures to indicate the position and direction of set accessories, men and lighting elements (projector heads, feet, reflectors scrims and nets, etc.) must give rise to real movements: approaching, moving forwards or backwards, tilting, raising, moving to the left or right, lowering a projector, etc. This is the stage involving the greatest number of coordinating gestures. The lighting acts like an air-conditioning system, not only because it is hotter under the projectors, but also because the space of the demonstration is thus framed by humans, who surround the shooting area, forming a wall of lights around it. At this stage, the field of the shot, more brightly lit, held by dozens of hands which bring it into existence, becomes clearly identifiable for everyone.

The assistant director places himself in front of the camera, in the position of the actors, so that information can circulate more effectively, and the assistants standing in for the actors constitute a reference for all the measurements. The cameraman gives his instructions to his assistants. The arms, hands and fingers serve not only to perform precise pointing gestures, they also move by approximation (higher or lower). This can only work because people are prepared to act as relays of instructions for each other, expressing them once again in the form of gestures.

In this way, the assistants extend the cameraman's indications with a great many gesticulations and the stunt director conveys them to his team. If it is pointless for a lightman to know the screenplay, he must, on the other hand, have enough intuition to foresee and anticipate what he will be asked to do. Young lightmen 
generally accompany more experienced ones and content themselves with following the orders of their seniors, who know from experience, once the order of the take has been given, where to position their equipment. Knowledge of the shot to be filmed thus reaches all the members of the production crew, by means of a set of relays that dictate the positions and directions to adopt. The information spreads to the four corners of the set, even if it is subsequently slightly modified or elaborated upon, for there is nothing clear-cut or obvious about this circulation of information.

The extras at the other end of the set are usually kept informed by the junior artists supplier, but the latter, if he is going to be ready in time, must make a considerable effort to fetch the information from as close as possible to its source, i.e. the place where the director and cameraman have done their "creative wandering". In this way, the image gradually acquires its tangibility, through successive stages; it becomes concrete through the different human interactions that give it a palpable form. In the next part of the article, we shall examine the most delicate manoeuvres, which take place between the director, the actor and those who represent or stand in for the latter during the take.

\section{Assistants, dancers, extras and the miracle of coordination}

Different directors vary greatly in the way they demonstrate movements to actors. This is certainly the most delicate stage in the process of materializing a take. Most often, the director does not content himself with simply indicating a position or movement to an actor, he performs it before the actor's eyes. We have seen Phalke do this. The demonstration depends on the desired action. Theoretically, at this stage, the number of possible gestures is infinite, which was not the case before. When it comes to expressing camera movements, (tracking, high angle shots, low angle shots, close-ups, etc.), the possibilities are limited. But the gestures used to direct actors consist in veritable accompaniments of the action, or measures that lead the actor to a given movement by getting as close as possible to him, to orientate the whole of his body as best one can. This work usually involves the use of three different categories of relay: assistants to act as mirrors, supporting men and doubles.

The following clips will help us to grasp the systems of demonstration most commonly used by choreographers and fight masters. The choreographer's or fight master's assistant demonstrates the movement to be made, and this is then repeated by the actor. When he has finished playing his role of substitute, the assistant then retires from the field of the take so the actor can take his place. A choreographer or fight master may have several assistants to act as mirrors (one assistant for the dancers, another for the star, for example, and another for the extras). This leads to complex systems with multiple mirrors.

\section{See video clip 7 http://www.qualitativesociologyreview.org/ENG/Volume8/videos/video7.php}

Let us watch the filming of an everyday song in an unspectacular setting, with simply one female dancer and a few male dancers. The choreographer has been invited by the director to choreograph the music bequeathed by the composer. He does not know the scenario, and he does not need to for the purposes of his work. He only knows that he must put into images a song with a South-American feel, with a young model whose first role this is as an actress. In fact, the director himself does not know exactly where he is going to fit this song into the film during editing, but this 
does not prevent him from being present and having clear ideas about what sort of choreography he wants.

The choreographer turns up at the shoot with his team of assistants and dancers and practically takes over control of the take. No choreography has really been prepared in advance. And the choreographer has decided not to give much time to this film, because he has other films to work on and he feels he is being underpaid. This is of little importance because, as we shall see, he has dedicated assistants, whose commitment must be total (unlike their boss) and without whom there could be no choreography.

Here, the movements are worked out on the very site of the shoot. Watching the dynamic of the take, we can see that two essential figures serve as mediators between the dancers, the actress and the choreographer. They are entrusted with the task of conveying to the actress the movements developed by the choreographer. Often, in fact, they have conceived these movements before the choreographer himself, and the latter draws on what they propose as if drawing from a pool of possibilities or choices. These "walking memories", the assistants, serve as stand-ins during the rehearsal, and then withdraw from the scene. So there are phases of filming, re-filming and rehearsal and phases of conception between the takes when the choreographer turns to the director and to his own assistants, serving as standins for the leading actress who will then replace them.

All this takes place in "fast motion" or in a state of urgency. And it is probably because of this acceleration and urgent division of tasks (between those who propose or suggest and those who perform) that Bombay filmmakers often say that "everything here is improvisation". Instead of one large phase of writing and another of filming (or, in the case of a dance scene, one large phase of devising the choreography followed by another of performance), there is a multitude of small cycles of conception/rehearsal/shooting and re-shooting. Here, the take really becomes a place of gestural conception (and not simply performance). There are many people to be managed and departments to coordinate on a shoot, and there is always something miraculous about this coordination. The camera is there to capture the best coordination, however brief or ephemeral it may be. The choreographer's assistants place and re-place the dancers, they distribute the positions and the background fills with male and female dancers who reproduce an identical sequence of steps.

The preparation unfolds in several stages. Firstly, the camera field is divided in two: the background, where assistants specifically allotted this task direct a crowd of participants, and the foreground, the favoured domain of the leading actress. The first sequence to be filmed, once it has been conceived, appears to be chopped-up, fragmented. And this is usually how choreographies are filmed. Short shots from different angles are preferred to one long sequence shot filmed several times. The "cut" is an integral part of the work of demonstration. It is harder to get the actress to reproduce an entire sequence than to pre-cut the action into small units (movements) that will be spliced end-to-end during the editing. This principle has been adopted by most of the choreographers of Bombay, not only because it enables them to work faster, but also because the more cuts there are the more possibilities one has of magnifying the action with zooms. The movement gains in iconic power when it is multiplied on the screen by numerous dancers and extras and frozen at the end of the take, filmed almost at a standstill. The assistants then have simply to indicate the posture to be held for the dancers to reconstitute the movement requested of them. So during a first phase, the action to be performed is internalised by each of the 
dancers as an automatism. They repeat the same movement while the assistant works on shifting it to the foreground with the leading actress.

The choreographer then mimes the tracking, introducing the camera into the human system of movement amplification he has just devised. The camera becomes an accessory of the choreography. This convenient way of progressing or of reaching an understanding on the set is also a mechanical and efficient means of internalising the distance between the subject being filmed and the camera. A priori, the actors express nothing that is not deliberate. If they do express a certain spontaneity and the choreographer introduces randomness into the dance, it has been worked on to such an extent that it is "synthetic randomness".

The choreographer puts a lot of work into naturalising or fluidifying what we might expect to appear robotic, but which never is, thanks to well-calculated disruptions. The spontaneity of a choreography, it is said in Bombay, depends on the many "filmi" breaks that are grafted onto it. These are not actions like the others, and the choreographer's assistants cannot substitute for the actor to show him which break can be introduced to spice up the take. On this occasion, it is up to the choreographer alone to propose something. The procedure varies little from one shoot to another: a large movement is conceived and then, from one take to the next, the choreographer seeks the little detail that will change everything, the wink, the sway of the hips or the well-placed slap that makes all the difference and captures the attention. This is where the complexity of the "filmi" resides. The break, once it has been suggested, is repeated several times, until it becomes an automatism. The cameraman, the choreographer and his assistants have reproduced the slap the actress gives her dancing partner fifty times before obtaining one good enough to be shown on the screen. The difficulty that the director and choreographer experience in getting the actress to give her slap the right orientation, speed and sinuousness show the extent to which the attachment of a gesture and an actor cannot be taken for granted, especially when it involves breaking the choreographic logic. The camera captures a successful action that may seem completely spontaneous on the screen, passing for a natural movement of the actor, whereas it has in fact required hours of repetition during shooting. Indian film choreographers adore "choreo-breaking", creating the favourable conditions for unpredictability to spring up in the foreground by placing a huge number of dancers performing repetitive steps in the background. The break is all the more effective when it takes place in the foreground and the movement to be broken has previously been reaffirmed in the background as an automatism, multiplied by the dancers who serve as foils to the leading actor. The more the dancers behave like robots, the more the actor who introduces disorder and nonchalance into the mechanism becomes human. Although the actor has had his movements on the set dictated to him and has spent his time copying his partners in order to internalise the automatisms, on the screen it is he who appears as the demonstrator par excellence who ultimately gives a lesson in humanity to the spectator. In the following paragraph we shall examine another example that sheds light on this reversal effect, or the way the demonstration is inversed when the back of the set is hidden. 


\section{Enemies and accomplices in action, or the art of pulling punches in an action scene rehearsal}

Two action coordinators, Moses and Kaushal, devise an action scene, more precisely a fist fight. Like the choreographer in the previous clip, the two fight masters have taken over the set with their troop of assistants and stuntmen. This time, however, the stakes and method of the demonstration are different. In brief, the problem they face is to find a way of throwing convincing punches which do not actually hit their target. For this purpose, Moses and Kaushal must conceive an "incomplete" action that looks as if it is complete. They must carry out an important work of consolidation around the movement (before, after, above, below, on the sides), amplify the impacts and reactions and make use of retinal persistence, i.e. the fact that human perception naturally completes the trajectory of an incomplete gesture when it is performed fast enough.

\section{See video clip 8 http://www.qualitativesociologyreview.org/ENG/Volume8/videos/video8.php}

Here, the demonstration calls for less power than the take, it is slower and the movements are broken down one after the other. The sequence is divided into actions and reactions with the assistants, to be quickly appropriated by the actor. Moses and Kaushal's men are professional amplifiers of action. It is then up to the actor to polish the action, so that it appears smooth, and to give it more power. The actor's double now takes over the action to coordinate the other stand-ins and show them how to hit the actor, throw him, strangle him, grab him, etc. Moses confirms the figures and positions. The actor takes his place once again at the centre of the stage and the cameraman arrives to define the frame. Moses then takes control of the frame to show the cameraman the best angle. Meanwhile, the actor has internalised the earlier demonstration and the cameraman shows everyone clearly the movement and frame he is going to use. The actor has therefore successfully been led to perform a whole sequence of movements by surrounding him with a certain number of people charged with the task of devising the sequence (during the demonstration) and then performing it with him in front of the camera. As in the previous case, the movement has been carried by a system of men, an army of demonstrators who do not totally disappear from the final shot, remaining in the picture in a reversed role, having abandoned their initial function, ceasing to act as models of reference. In the action scenes, what makes the actor appear heroic, or what makes this final role reversal from "demonstratee" to demonstrator possible, is the acceptance that only the leading actor can break the dynamic of the fight or turn it upside-down (in the style of choreographic breaking), all the more so since the system of men who carry it is wholly orientated towards enhancing his abilities as a warrior and presenting his gestures as deadly blows. In this sequence at least, he is the only one who can deliver fatal blows, sometimes by a simple movement of his index finger, because he is surrounded by a group of enemies who are in reality accomplices or foils. The supporting men carry a heavy burden on their shoulders, defeated and won over from the start, even before they get beaten up. 


\section{Stunt doubles, or how to convince an actor not to jump from the first floor}

In the preceding clips, we have identified several relays of demonstration (the use of assistants, dancers and supporting men) which also function as means of amplifying movements and which depend on a more or less complete camouflage of the other side of the take. The diversification of relays does a lot to lighten and focus the actor's work, limiting his role to performing the right movement, the positioning of which has been pre-defined by his entourage. But what happens when the degree of risk or difficulty of the take is increased, when a complicated stunt is introduced, for example? Of course, the actor runs the risk of confirming to an even greater extent that he is there simply to perform the final flourish in a process that is always laborious but that is endowed, by the star's arrival on the set, with an aspect of repetitive tedium. However, the introduction of an element of danger may call for a radical reorganisation of the demonstration. A new group of intermediaries appears, the stunt doubles, increasing the complexity of the take and representing one of the possibilities of recourse most often used in film. As we have already seen, when the actor is accompanied, his entourage fades away at the right moment or swaps status with him so that he can appropriate the action he performs. The assistants disappear when necessary, the dancers charged with enhancing the slightest sway of his hips play their role of background automatons during the take, although they are often much better dancers than he is, while the martial arts experts no longer appear in the picture as anything other than subjugated specialists, understating their talents to the benefit of someone much less skilful than they are. The double charged with performing a stunt in place of the actor does not entirely disappear either, he infiltrates the final picture, also camouflaged and modified, but not in the same way as the dancers and supporting men. The double pretends to be someone else, at least partially (in his silhouette, back, fist, etc.) but at the same time he reminds the actor of the latter's inability to perform a movement without a skilful system to support him.

In the following clip, the actor has refused to jump from the top of a platform. The stunt director has tried to persuade him, but the actor really does not feel like doing it and would rather someone else jumps in his stead. The stunt director has placed cardboard boxes on the ground to soften the fall. The jump takes place; the stuntman hurts himself slightly, but almost certainly less than if there had been no boxes there to cushion his landing.

\section{See video clip 9 http://www.qualitativesociologyreview.org/ENG/Volume8/videos/video9.php}

A second jump is then organised and this time it is not the start of the jump that is filmed, but the explosive landing on a glass table, which shatters at just the right moment thanks to electrical discharges fixed under the glass. This time, the stuntman's injuries are more serious, his hands are covered in blood, and everyone congratulates him on his wonderful jump. Once again, the action must be magnified, the gesture must be celebrated, and to do so the action is divided into two stages or "peaks": the impulse and the impact. If the jump had been filmed all in one go, it would have been much trickier to achieve this contrast. The cut necessitates two systems for amplifying the movement, however rudimentary they may be, a pile of boxes in the first case, a stepladder and a human structure in the second to enable the stuntman to fall precisely and to achieve the full extent of the jump.

It is by focusing on the impulse and the impact that the film crew succeeds in concealing the use of a double. By filming one close-up of the point of departure and 
another of the body smashing into the table, the camera can avoid the zone of the face, which might have betrayed the ploy. So the action that will finally take place on the screen has never actually happened as such; it is the synthesis of two real actions, just as the actor that will be seen performing on the screen is in fact composed of two bodies. The final synthesis would happen later in the head of the audience.

It is worth noting that journalists interested in the film world and its mechanisms generally treat duplicates as if they were a particularly murky system to be demystified, a perfect symbol of the other side of the set. We regularly come across articles in the press about the "men of the shadows" who perform stunts for famous actors. This expression is not really accurate. It would be more correct to speak of men who appear camouflaged in full light. Stunts using doubles are commonplace, they are stage routines in the same way as the assisted choreographic shoots or action sequences with pulled punches described above. These different cases all belong to the same set of demonstrations, and the example of the stunt double is at the same time both extreme and normal, with the actor stepping aside physically to make way for his demonstrator, for in this case too the double has performed as a demonstrator, not as an actor. A few words from the action coordinator are all it requires for him to know what to do and how to do it. The stuntman is much better at jumping than the actor himself, and does not need to have the action explained to him before throwing himself into space. With the double, the system that usually supports the actor functions without him. And the production team saves time by not having to rehearse the scene with the actor. They have removed one of the stages in the relay chain of demonstration. Paradoxically, the use of a double does not add a system, it removes one. It is a short-cut in filming.

\section{Demonstration scaffoldings and assisted virtuosity}

The variety of demonstrations performed for actors depends very much on the clarity or visibility of what has to be done, of the screenplay or pictures to be realised. For, as we have seen, there is a direct relation between the gestures on the set and the opacity of a project, screenplay or scene. Ideally, one should enlarge the range of comparison to other film industries, to other styles of direction and alternative ways of supporting the image by demonstration scaffolds, because there are other ways of creating a network of human assisted creation on a film set. If there is a cruel lack of comparative data available in this field (ethnographies of film sets are still very rare, and we have said earlier what we think about the usual "making-ofs"), we can at least indicate one way to take this comparison further, relating the way actors learn how to perform a shot on a film set to common theories of apprenticeship.

The Russian theoretician of learning Lev Vygotski (1934) proposed the notion of "Zone of Proximal Development" (ZPD), which became popular in the sciences of apprenticeship to describe the distance between the actual level of learning of an apprentice who learns alone how to solve problems and the potential level of development that he could attain with the help of an expert or a more advanced partner. Vygotski used a complicated terminology to say something quite simple: assisting the apprentice enables him to achieve a result that he could never attain on his own. We have seen that the Bombay film studios exploit this basic principle of apprenticeship to get the actors to do things they could never have done without assistance. They go even further by multiplying the demonstrators and the people who will make the action easy to digest for them, using devices to fragment the shot 
into smaller elements or special assistants who will act as "mirrors" during the shot to remind them of the gesture to be made. One can well imagine other ways to deal with the necessity of demonstration on a film set, and many film-makers have experimented, in India as well as elsewhere, other styles of direction and other acquisition methods for the actors.A sequence of great lucidity, one of the first making-ofs in the history of the movies, "How Films are Prepared", by Dadasaheb Phalke is a short study film that Phalke screened with each of his full-length films to explain the technical aspects of film-making to his audiences. This is a paradigmatic film not only for film theory, but also for gestural anthropology and the study of demonstration devices. The gesture appears as what it really is, an explanatory enterprise or an expenditure of energy needed to make clear, in this case to the audience, what the director does and how he does it. Phalke mimes technical operations to help the spectator understand what film-making consists of. $\mathrm{He}$ is filmed with the actors, showing them the work to be done, in the prop and costume room and during construction of the set. The demonstration is iterative and emphatic, for Phalke is seeking to explain the whole art of filmmaking.

See video clip 10 http://www.qualitativesociologyreview.org/ENG/Volume8/videos/video10.php

Paradoxically, Phalke simulates the work of writing at the end of the film, rather than the beginning ("thinking and thinking again", the insert title tells us), and it is the gesticulations used during shooting and their power to coordinate that are highlighted. These demonstrations are of different types and suggest that the take requires a large number of gestural manipulations and explanations: stylised, "melodramatic" gestures expressing the director's attitude, marked by a theatrical heritage, gestures of pointing and orientation, gestures for positioning the actors. This work of demonstration appears to have been all the more essential because Phalke's actors had no experience of acting for the camera and had to learn everything from scratch. Phalke redoubled his mimes to get the actors to understand the actions to be accomplished in front of the camera. These demonstrations, the purpose of which was to realise an image or to get the actor to internalise a previsualised image, do not have the same status as those in which Phalke mimed editing or writing and which sum up a technical manipulation in the twinkling of an eye. However, we cannot separate the two, for what is striking about the way Phalke presents himself as demonstrator, director of actors and technicians all at the same time, is the distance at which he operates: the actors are directed at a distance, a "proximal" distance. What they produce with their bodies is recorded at a distance by the camera, and it is also at a certain distance that the film is examined (neither too close nor too far away). Filming means going back and forth between the actors and the camera, showing them close-up the work to be done and then filming from further away.

Film is the art of remote control, and if we follow Vygotski's theory, Phalkes' mimetics is a relatively classic model. To show his novices how to be film actors, Phalke behaves like a mirror in front of them, he never pushes them around, maintaining the visual distance needed for his actors to see him as an image to copy. His gestures are there to compensate for a lack of knowledge on the part of his actors, who do not know what they ought to do. They are also a means of inviting the actors to tame the amplification machine constituted by the camera, which produces a magnified image of them. When Phalke returns to his position behind the machine, his status has changed in the eyes of the spectator, he is no longer simply a 
gesticulating demonstrator, he has become a master of the "cine-guidance" of actions.

An alternative way to deal with demonstration is offered by Federico Fellini. Gideon Bachmann's film of Fellini at work during the shooting of Satyricon might well become a cult film for ethnographers working on film sets. It will help me to conclude this analysis. Fellini does not go in for the long chain of mediators of mime, he does not burden himself with translation, but he intervenes from time to time directly on the actor's body. When Fellini directs his actors, as Bachmann's film demonstrates, he does not hesitate to turn their heads in the direction he wants ("to the left, to the right") or to push an actress to express her sensual pleasure by pretending to slide his foot between her legs.

See video clip 11 http://www.qualitativesociologyreview.org/ENG/Volume8/videos/video11.php

The contrast between these moments of direct manipulation and the chains of intermediaries analysed above is too striking to be overlooked. They represent the two extremes of persuasion between which any production team fluctuates in its own manner. On the one hand, the respectful but constraining distance which necessitates a multiplication of gestures to get the message across, and on the other, the interventionism which can go as far as manhandling the actors to "get them to live unbeknownst to themselves", as Fellini puts it in his interview with Bachmann. It is equally difficult, he explained, to direct trained actors and absolute beginners; the former have to unlearn the film work they have done and the latter must learn to let life escape despite themselves. By not letting his actors see the scenario, Fellini kept them as "pure" as possible for the shooting, so that he could obtain what he wanted. More than conjuring, which had inspired Phalke, or hypnosis, which has inspired other directors, Fellini's style of directing actors was inspired by puppeteers.

From childhood on, Bachmann underlined, Fellini had had a pronounced liking for puppets, getting his schoolfriends to pay for the shows he organised on the terrace of his house. Fellini transferred puppeteering onto the film set, where putting on the show is no longer a question of manipulating objects or people for themselves, but for the camera, and through the camera for the audience.

Without pulling on any strings, Fellini moves his actor's head so that it responds, at a certain angle, to the image "in the name of the audience", and because "it looks good", as he says to the actor Martino on the set of the Satyricon.

All instructions or interventions are conveyed elsewhere, within the camera that automatically swallows up whatever it is presented with. If Fellini could make the sort of declarations he did about actors without appearing a shocking manipulator, it was because he was a past master in the art of getting actors to turn in performances that they themselves did not expect, by directing their slightest movements. The actors themselves accepted this manipulation, because they knew that things would escape from them that they might not control, but that someone else was supervising for them and that would be good to watch.

The actors of Fellini who expressed themselves in front of Bachmann's camera were happy puppets, emphasising the pleasure they experienced in this form of cineguidance, where they were, admittedly, forbidden from reading the screenplay and therefore anticipating what they could do, but where they were also liberated from the constraint of self-assessment. However, we must avoid the temptation of branding Fellini with a specific work protocol. He himself believed that he had no system, that he moved forward case by case. We can only concur on this point, for on set he appeared to fluctuate between different ways of managing the relation with his 
actors, sometimes returning to more classic forms of remote control. In an erotic scene in the Satyricon, for example, it is at a distance that he directs the take with his hand, imposing the atmosphere of the scene and indicating when the actors should kiss each other during the take.

Fellinian intimism is above all a matter of the hand. It encircles and guides the actors in the action. "Watch my hand" he says to Martino during the take.

If, at certain moments, Fellini allowed himself liberties that other directors forbade themselves, at other moments, too far away from his actors, he seemed to lose control or to have to gesticulate for all he was worth to get his instructions followed.

In his interview with Bachmann, Fellini gave precious information about his style of directing: rather than letting the actors read the scenario and then having endless brainstorming sessions with them, it is better to create an atmosphere, a favourable climate, so that "the actors breathe the air of the film". It might be objected that Fellini had a very personal way of directing actors. In fact, however, the individuality of Fellini's method is less striking than its absence of singularity. He used the same technical gestures as other filmmakers, and his body movements, apart from the simulations of camera movements, were just as dependent as those of other directors on the actions that he wanted his actors to perform. It is when they are indexed to the movements the actor must make that the mime of Fellini and that of Phalke become singular. The actions they seek to get their actors to perform make all the difference. Like those of other directors, Fellini's direction of actors implies, to the contrary of a fixed code or mode of communication, the establishment of a "remodelling" contract, where the actors agree to let themselves be guided by someone who would probably be incapable of doing what they do, but who is as aware or more aware of their visual plasticity and the effects it will produce when magnified by the camera. As Fellini said, "First I look for physiques and then I work on them with the actors".

From the point of view of the primacy of the gestural engagement, what happened with Fellini's actors is not far removed from what we have observed on the Bombay film sets of the 1990s. On the other hand, the way in which the actor's "virginity" in relation to the script is maintained in the two cases appears to stem from almost completely opposite motives. In one case, it leads to the centralisation of the demonstration in the unique figure of the director, and in the other it leads to the multiplication of assistants and experts around the actor. In the case of Fellini, ignorance of the screenplay was deliberately cultivated in order to maintain the singularity of the characters he had in mind. In the Bombay of the 1990s, many believed quite simply that they had no need to read the screenplay to know their role, but it was for other reasons than those given by Fellini. Many actors (there are of course a few exceptions) would prefer to take part in a carefully assisted impregnation "on the spot" rather than spending six months internalising their character. Actors have integrated the fact that what is locally called the filmi, a style of gesture, of dialogue, a certain form of mannerism, requires its own set of procedures of impregnation or assimilation. The actor gives his best performance when helped by a solid process of fragmentation of the shot, through human scaffolds like the ones we have described, producing the conditions for the expression of an assisted virtuosity. 


\section{Conclusion}

This little detour by way of Fellini, who sometimes interrupted the chain of explanation in favour of a direct hold on the actors' bodies and a certain roughness in the relation of manipulation, throws light on the variety of systems of demonstration used on film sets in general. Breaking the normal scheme of learning, Fellini shows that the actor doesn't need to internalise the action in his mind in order to reproduce it; he can be led to perform a certain action through a corporal process. In its most extreme version, this mode of direction can result in the actors being relieved of the need to memorise, when the director repeats each line of the dialogue to the actor while he is acting. Not only was this type of device popular in Cinecitta, but it has been experimented many times in the history of cinema (see the recent Don Quichotte by the Catalan film-maker Albert Serra). Such scaffolds show what is at stake in the "proximal zone" involving the directors and actors, sometimes giving rise to new ways of optimising the learning process necessary to achieve the shot. This optimisation has taken a particularly efficient form in the Bombay studios, through the assistance of human scaffolds (multiplication of assistants acting as mirrors, supporting men, demonstrators), the fragmentation of shots and sequences, and the adroitness of the exchanges of position between actors, doubles and demonstrators. But these practices should not eclipse the fact that many other methods have been experimented, especially in the field of the cinema d'auteur.

In every instance, it is the distance from the camera that has to be managed, somehow or other, and that the protocols of demonstration seek to remedy. We can draw some principles concerning the way the take is supported by a process of demonstration and gestural manipulation. Video enables us to transcend the vague impression that filmmakers use "sign language", to draw finer distinctions and see exactly what the difference is between gestures that transpose or concretise an internal image (translating a story, narrating a scenario with the help of one's hands, for example), those that project a shared object or whose purpose is to objectify it for others (positioning the frame, the camera movement, before the take or in between takes), devices that coordinate and so help to set up the take (positioning the actors, lights, accessories, etc.) and demonstration scaffoldings that reproduce or whose purpose is to be performed in imitation (executed by the assistant or the double in front of the actor, so that he can perform them in turn). Inevitably, there are more movements of transposition in the early stages (see the narration session) and an increase in reproductive movements in the later stages, as the moment of the take approaches. The quantity of reproduction increases or accelerates as we get closer to the take, while the quantity of transposition and projection decreases, taken in charge by the camera.

Gestures are used to fulfil various needs, and their power of persuasion is so great that one can make a film without ever leaving the gestural plane. As one gets closer to the take, the demonstrative technique widens and diversifies (assistants, supporting men, doubles, etc.). This observation precludes us from reducing the modes of demonstration on the film set to a "sign language", unless we separate the gestures from the intermixing of human forces that gives them their meaning. The work of demonstration and accompaniment needed for a take varies according to the difficulty of the movement, the actor's experience and ability to internalise what is asked of him, the number of elements that have to be coordinated (props, special effects), but even the simplest actions entail an impressive number of prior demonstrations: for an action to take place on the screen (running, jumping, falling, cutting someone's throat, slapping, punching, shooting), the take requires a greater 
number of manipulations than the same action carried out for real. Shooting someone for real requires a good aim, it is no easy task. Pretending to shoot with verisimilitude in front of a camera does not need the same precision, but it is more onerous to perform in terms of collective coordination: in addition to the standard equipment for filming any interaction, it requires, at the very least, a pyrotechnician, a weapons master and a special effects supervisor to simulate the impact of the bullets or repair the damage before each new take. The gestural and human resources called upon at different stages of the conception constitute different facets of the manual mode of the take. Unfortunately, the various ways of playing on this mode are not accessible through the usual making-ofs, and my aim has simply been to suggest a few concepts to deepen our exploration of a field that certainly requires more ethnographical case studies, not only in Bombay but also elsewhere.

\section{References}

Delaporte, Yves (2002) Les sourds c'est comme ça, Paris: Editions de la MSH.

Goodwin, Charles (2003) "Pointing as Situated Practice." Pp. 217-241 in Pointing: Where Language, Culture and Cognition Meet, edited by Sotaro Kita. Mahwah, $\mathrm{NJ}$ : Lawrence Erlbaum.

Grimaud, Emmanuel (2004) Bollywood Film Studio ou comment les films se font à Bombay. Paris: CNRS Editions.

Haviland, John B. (1993) "Pointing, gesture spaces, and mental maps." On-line text. http://www/cs/uchicago.edu/l-c/archives/

Hutchins, Edwin and Leysia Palen (1997) "Constructing Meaning from Space, Gesture, and Speech". Pp. 23-40 in Discourse, Tools and Reasoning: Essays on Situated Cognition edited by Lauren Resnick, Roger Säljö, Clotilde Pontecorvo, and Barbara Burge. Springer-Verlag.

McNeill, David (1992) Hand \& Mind: What Gestures Reveal about Thought. Chicago: University of Chicago Press.

Piette, Albert (1996) Ethnographie de l'action. Paris: Métailié.

Rosental, Claude (2005) "Making Science and Technology Results Public. A Sociology of Demos". Pp. 346-349 in Making Things Public edited by Bruno Latour and Peter Weibel. Cambridge MA: MIT Press. .

Vygotski, Lev (1934) Pensée et langage, Paris: La Dispute, 1997 for the French translation 


\section{Appendix}

Video clip 1 http://www.qualitativesociologyreview.org/ENG/Volume8/videos/video1.wmv Video clip 2 http://www.qualitativesociologyreview.org/ENG/Volume8/videos/video2.wmv Video clip 3 http://www.qualitativesociologyreview.org/ENG/Volume8/videos/video3.wmv Video clip 4 http://www.qualitativesociologyreview.org/ENG/Volume8/videos/video4.wmv Video clip 5 http://www.qualitativesociologyreview.org/ENG/Volume8/videos/video5.wmv Video clip 6 http://www.qualitativesociologyreview.org/ENG/Volume8/videos/video6.wmv Video clip 7 http://www.qualitativesociologyreview.org/ENG/Volume8/videos/video7.wmv Video clip 8 http://www.qualitativesociologyreview.org/ENG/Volume8/videos/video8.wmv Video clip 9 http://www.qualitativesociologyreview.org/ENG/Volume8/videos/video9.wmv Video clip $10 \mathrm{http}: / /$ www.qualitativesociologyreview.org/ENG/Volume8/videos/video10.wmv Video clip 11 http://www.qualitativesociologyreview.org/ENG/Volume8/videos/video11.wmv

\section{Citation}

Grimaud, Emmanuel (2007) "The Film in Hand Modes of Coordination and Assisted Virtuosity in the Bombay Film Studios." Qualitative Sociology Review, Vol. III Issue 3. Retrieved Month, Year (http://www.qualitativesociologyreview.org/ENG/archive_eng.php)

Volume III Issue 3 www.qualitativesociologyreview.org 